\title{
Redesigning the User-Interface: The Use of Colours in nopE-Commerce Enterprise Software
}

\author{
Afeez Babatunde Siyanbola, $\mathbf{P h D}^{1}$ \\ Akinmoye Oluwambe ${ }^{2}$ \\ ${ }^{1}$ Department of Fine and Applied Arts, Olabisi Onabanjo University, Ago-Iwoye, Nigeria \\ ${ }^{2}$ Department of Fine and Applied Arts, Mountain Top University, Ibafo, Nigeria
}

Article History: Submitted 6 June 2021; Revised 4 July 2021; Accepted 5 August 2021

Corresponding Author: Akinmoye Oluwambe, Email: oakinmoye@mtu.edu.ng

DOI: https://doi.org/10.3126/sjah.v3i2.39414

Copyright 2021 (C) The Author(s). The work is licensed under a Creative Commons Attribution 4.0 International License (CC BY 4.0).

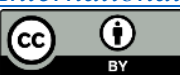

\begin{abstract}
This paper appraises the relevance of e-commerce enterprise software in contemporary business management. Enterprise packages are technological applications that automate business activities and improve efficiency in the business workflow. The study enunciated the critical role of administrating the backend of enterprise software to manage the front-end which is accessible to users. The user interface of e-commerce enterprise backend is essential in enhancing user's performance on the software. The study explores the psychological and physiological properties of colours in redesigning the nopE-commerce enterprise software for the backend user interface to enhance the efficiency of the administrators. The objectives of the study are to download the existing the backend of nopE-commerce enterprise software, to recreate the backend of nopEcommerce enterprise software and to introduce colours into the redesigned user interface backend of nopE-commerce enterprise software. The redesigned user-interface was subjected to the evaluation of one hundred (100) selected back-end administrators working in Lagos. The responses of participants were analysed using the 5-point Likert Scale to generate mean results. The results indicated that colours stimulate actions and feelings, user interface colours in virtual environment determines the efficiency of the system and the creative interplay of orange and blue colour in e-commerce back-end user interface enhances the performance of backend managers.
\end{abstract}

Keywords: Enterprise software, back-end, interface, colours, e-commerce

\section{Introduction}

Enterprise software is a collection of computer programs with shared business applications, tools for modeling organization workflows, and development of tools for creating applications that are tailor-made for organizations (Laudon and Laudon). Enterprise software are composite application, that refers to a complex software 
platform (Beal). According to (Hoots), describes Enterprise Application Software (EAS), as a software system specifically developed to cater for the different needs of corporate businesses. Basically, enterprise software enhances enterprise-wide productivity and efficiency through business logic support.

Lisa Schwarz noted that the core business functions of enterprise solutions include fostering enhanced alliance, aligning operative processes and providing fast data visibility within the entire organization. This integrated application enables the functions stated in the following accordingly:

- Analytics and reporting

- Customer support

- Order and inventory management

- Procurement

- Content management

- Marketing

- Pricing and promotions

Enterprise software is classified according to their usages. Each type of enterprise application is referred to a "system" because it integrates the diverse business workflow needs (Beal). Enterprise packages are technological applications that automate business activities and improve efficiency in the business workflow. Current developments have shown that enterprise software is being migrated to cloud computing. The infrastructure of enterprise application can be deployed online where the application can be accessed by the licensed computer devices through the internet on-demand. In some instances, organizations opt for a combined solution where cloud systems are fused through the local network. E-commerce enterprise platforms are also referred to "Shopping Cart" software. Typically, the contrast between ecommerce enterprise solutions and other enterprise platforms is the integrated shopping cart features in e-commerce platforms that catalogues products and automatically process the payments of purchased products inclusive of handling charges on an online store in real time.

Kate Hoots noted that the features of an e-commerce enterprise solution are as follows:

1. Offers unlimited everything (number of products, product variations, online storage, bandwidth, site traffic, etc.)

2. Includes premium web features like custom SSL certificates, SSO (single signon, where a single login gives you access to more than one service), and Google Trusted Store tags

3. Order and inventory management.

4. Payment gateways have more competitive rates and fees

5. Multi-channel and multi-store features

6. Integrated Point of Sale (POS) features

7. Customer Relationship Management (CRM) features

8. Personal account managers, assisting in training, and technical support

Enterprise applications are characterized by their user interface, front-end and back-end which are relative. The users interact directly with the "front-end" application while the "back-end" applications directly feed the front-end services, typically by its connection with the specified resource or having the capability to communicate with the required resource (Castro). The front-end is the areas accessible to the end users of the applications. In e-commerce enterprise solutions, the front-end refers to the "storefront". The areas accessed by visitors to an e-commerce store include homepage, category pages, sub-category pages, product details pages, check out pages and others. The 
content on the pages are dynamically created by the application based on the configuration of the database and the content fed in from the backend. E-vendors manage web store from the back-end side of the enterprise solution. The store managers add and edit product images, prices, discounts, shipping and payment information and others.

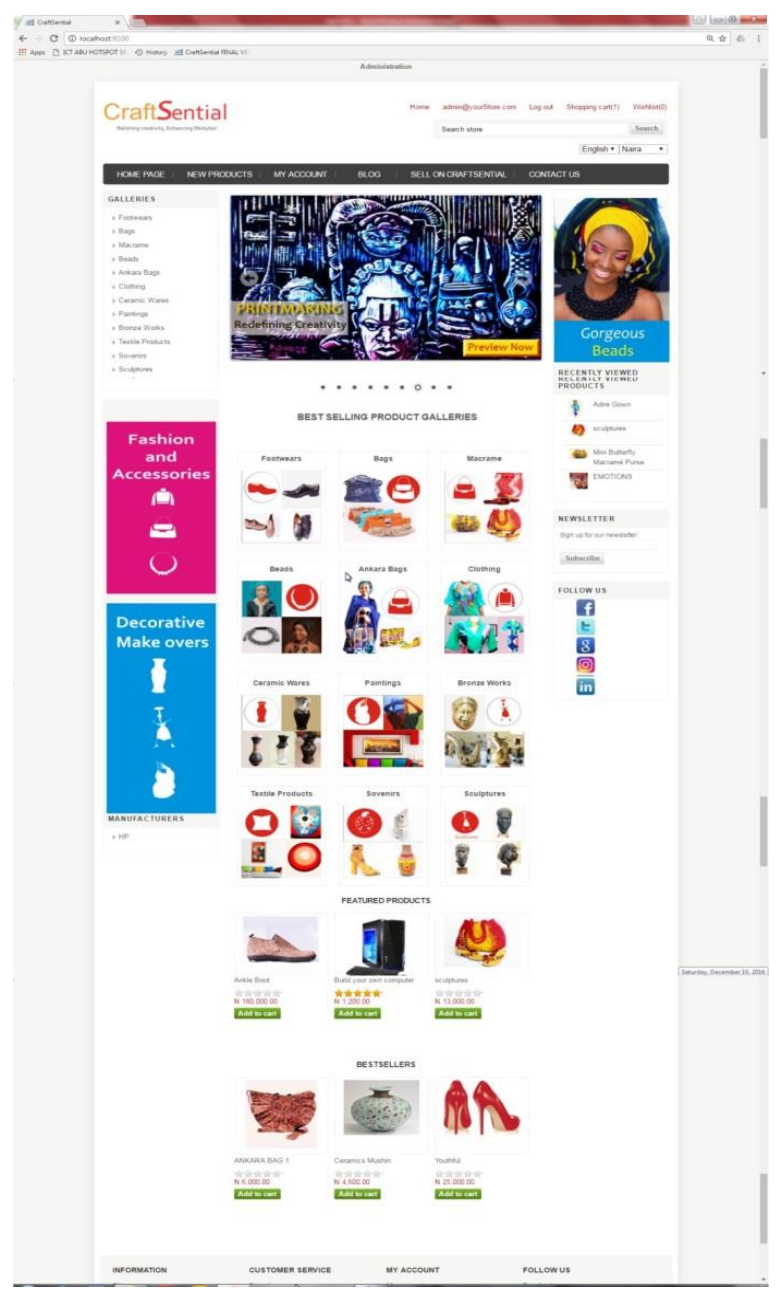

Fig. 1. Front-end of nopEcommerce Solution

Source: Author's fieldwork (2019).

Typically, the backend of enterprise software solutions is not visually engaging and attractive in terms of "look and feel". Buttons on the navigation bar and drop-down menus are adorned in black colours which makes them less engaging and interactive. An average worker could seat down all day feeding the back-end side of the application. Therefore, the user interface of e-commerce application back-end can be enhanced to consistently arousing the interest of the user.

\section{Types E-Commerce Enterprise Solutions}

Some of the existing e-commerce enterprise solutions are discussed below:

\section{BigCommerce}

This e-commerce enterprise solution is an open architecture created to effortlessly integrate contemporary e-commerce shopping features (Pelet). Single-click integrations with foremost ecommerce softwares that allows users to simply connect to business-critical software. Flexible APIs and webhooks enable users to integrate fast and 
cost efficient, that enhance operational efficiency and guarantees the platform business requirements (Pelet).

\section{nopCommerce}

This is a robust ASP.NET driven open-source e-commerce application. It is a solution with robust features suitable for different users and potential online businesses (nopCommerce). This platform has a rich architecture with access out of the box features. nopCommerce has an active community of users and developers, which provides assistance to other users contributes with code, plugins and other extensions and helps to the planning of the roadmap (Glasskeys). The application partners with over 107 solution partners domiciled in 37 countries creating custom development, graphic themes and providing other services (nopCommerce).

\section{WooCommerce}

WooCommerce is an open source e-commerce plugin supported by WordPress. The application is crafted for medium scale and large-scale online businesses using WordPress. The plugin is renowned for its simplicity to installation and customizable free product template. WooCommerce adopts a formal partnership program. WooCommerce advise users to collaborate affiliated WooExperts for their online projects (WooCommerce).
Aim
The aim of this study is to introduce colours in the redesign of the back-end user interface of nopE-commerce enterprise software. The specific objectives are to:
1. download the existing backend of nopE-commerce enterprise software
2. recreate the backend of nopE-commerce enterprise software
3. introduce colours into the redesigned user interface backend of nopE-commerce enterprise software

\section{Literature Review \\ The Psychology of Colour}

Human responses to colour usage are typically dependent on personal preference, experiences, upbringing, cultural differences and others. Colours are emotive and persuasive in influencing actions and feelings. However, in a research titled "Impact of color on marketing," scholars discovered that an estimated $90 \%$ of impulsive judgments made by consumers on products are hinged specifically on colour, depending on the product (Ciotti). Males and females are impacted by colour in different ways. A study found that both genders favour the colour blue with $57 \%$ of men and $35 \%$ of women preferring it over other colours, though it is more heavily favored by men (Hallock). Colours are critical in visual identity, studies show that the interplay between products and color hinges on the perceived correctness of the color adopted by brand (Ciotti). Suitability of colours in an atmospheric is determined by the application and functions that takes place in such environment. The ambience of an environment has its impacts on the behaviours of the inhabitants. The psychological effects of colours are highlighted as follows:

\section{Red}

Red is stimulating, lively and very friendly, it appears to be nearer and grabs attention easily. Hence, it is used in traffic lights across the world. Its effect is physical; it stimulates us and raises the pulse rate, giving the impression that time is passing faster than it is (Pelet). 


\section{Blue}

Blue is mentally calming and soothing, as compared to the physical reactions related to red. Blue is also associated with intellectual appeal. It can be identified with cold, ice, distance, and infinity as well as calm reflection (Cherry). Strong blue influences sharp reasoning, soft blue calms and enhances concentration.

3. Yellow

Yellow enriches self-esteem, it stimulates confidence and optimism. Dominance of yellow and poor interaction with other colours can plunge self-esteem which causes fear and nervousness.

\section{Green}

Green depicts abundance and fruitfulness. The vegetation around are mostly greenish which indicate the availability of water. Green is the colour of balance based on its positioning on the colour spectrum.

\section{Orange}

The blending of yellow and red gives orange. Orange is inspiring and combines physical with the emotional. It supports the minds on issues of physical and emotional comfort and sensuality. It is a 'fun' colour.

\section{Pink}

Being a tint of red, pink arouse people physically and soothes. However, red is the only colour that has a wholly colour names its tints. Tints of blue, green, yellow, etc. are simply called light blue, light green. Pink is a feminine colour, is nurturing and physically soothing.

7. Black

Black absorbs all colours. Black has several psychological considerations. Black is basically the absence of light. Black is perceived to be a mysterious colour which is often associated with soberness. Black signifies strength, power, formality, sophistication and uncompromising excellence. It conveys absolute clarity, without nuances. The colour connects perfectly with white. Black gives an impression of weight and seriousness.

8. White

White ensues barriers, often a strain to the eyes. It communicates, "Touch me not!" White represent purity and conveys a sense of innocence. It depicts cleanliness, hygiene, freshness and simplicity. Visually, white colour is often used to indicate negative space in designs.

\section{User experience in Web design}

The look and feel of software is referred to graphic user interface (Aronhamukwaya). Interface enables human capabilities to interact with digital platforms with the aid of graphical icons and visual cues such as secondary notation, in contrary to text-based interfaces (Aronhamukwaya). It enables users to communicate with a computer through the use of symbols, visual elements and cues. Graphic design and typography are necessary in ensuring usability, prompting how users perform certain interactions and look and feel of the interface. Design aesthetics may enhance or detract the ability of users to use the functions of the interface (Norman 34). (Gube) defines user experience (abbreviated as UX) ease-of-use and perception of a system interface. The system could be a website, a web application or desktop software and, in modern contexts, is generally denoted by some form of human-computer interaction (HCI). Web design technologies, online games, social media networks, e-banking, e-commerce platforms and other assortment of web applications places premium functionality on HCI. The beauty of information technology platforms is the hedonic attribute of the 
products, which leads to pleasurable user experience (Coates, 214) and to increase satisfaction in users (Lindgaard and Dudek, 433; Tractinsky, Shoval-Katz, and Ikar, 141).

The user experience (UX) focuses on understanding what users need, value, their capabilities, and also their limitations on websites. (Jordan Patrick) suggested a pleasurebased design model anchored on the hierarchy of users' needs that comprises of four levels: safety, functionality, usability, and pleasure experience. John Sameer defines pleasure as "the emotive hedonic and tangible benefits derived from products". Usability of enterprise applications software's can be enhanced with lively colours garnishing the application user interface. Pleasurable user experience motivates workers to focus and give in their best while working on enterprise applications.

\section{Methodology}

The research design adopted by this study is qualitative and quantitative. The back-end user interface of an existing e-commerce enterprise solution was redesigned with the aid of Corel Draw graphics design package on the installed on a system. The existing user interface was screenshot and exported into the CorelDraw page. Thereafter, a replica of the interface design was sketched using the rectangular tool and Bezier tool on the software's tool bar. Page menu bar, fly-out menus were created with textual representation of information on dashboard using the CorelDraw package. Colours selected from the software's colour palettes were infused accordingly into the created boxes and columns to enhance the look and feel of the back-end interface. The population of respondents for this study are one hundred backend administrators from fifty companies that uses e-commerce platform domiciled in Lagos, Nigeria. The respondents were asked to evaluate based on their knowledge and familiarity with different enterprise e-commerce back-ends.

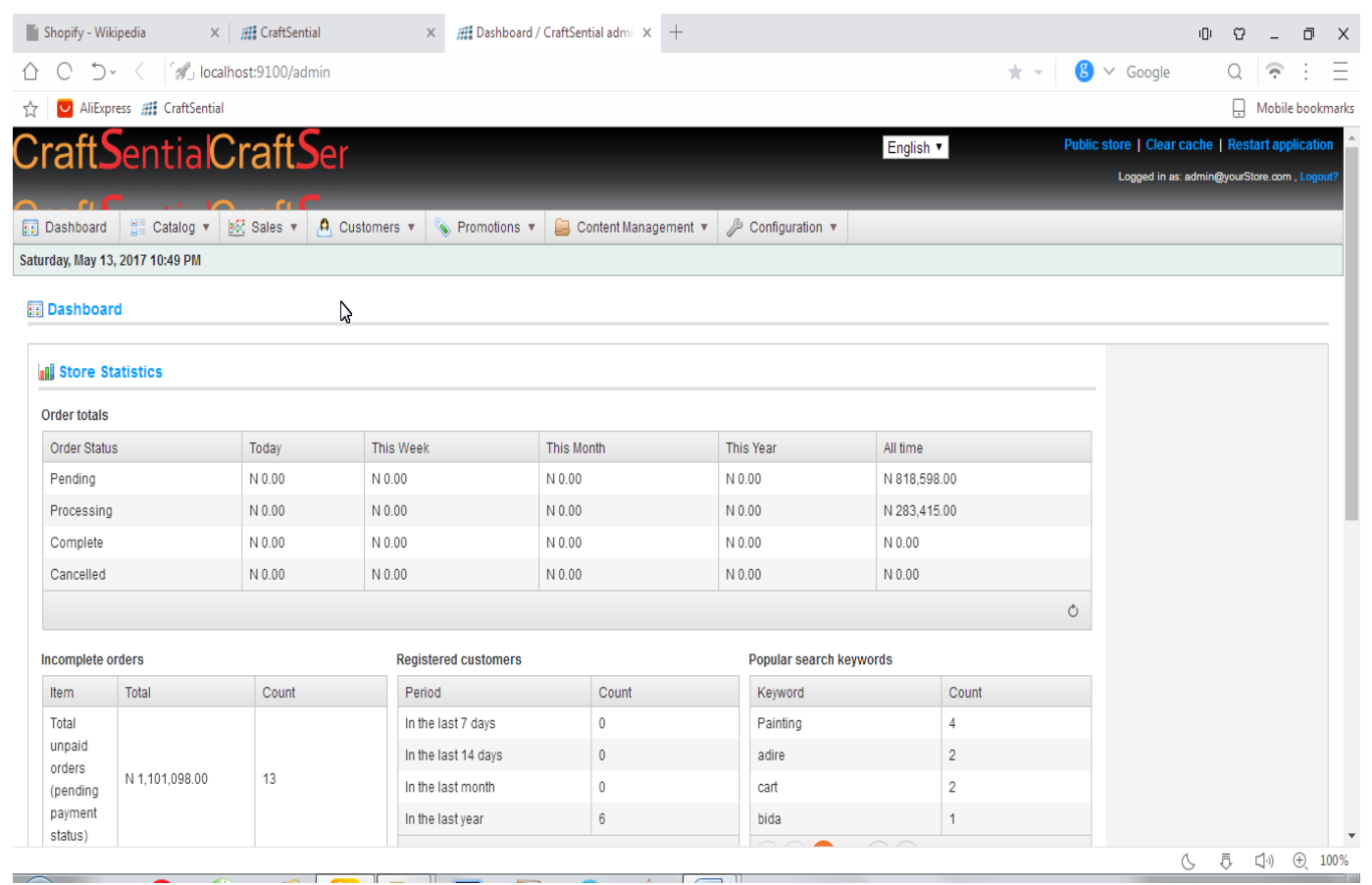

Fig. 2. Back-end of nopEcommerce Software

Source: Author's fieldwork (2019) 


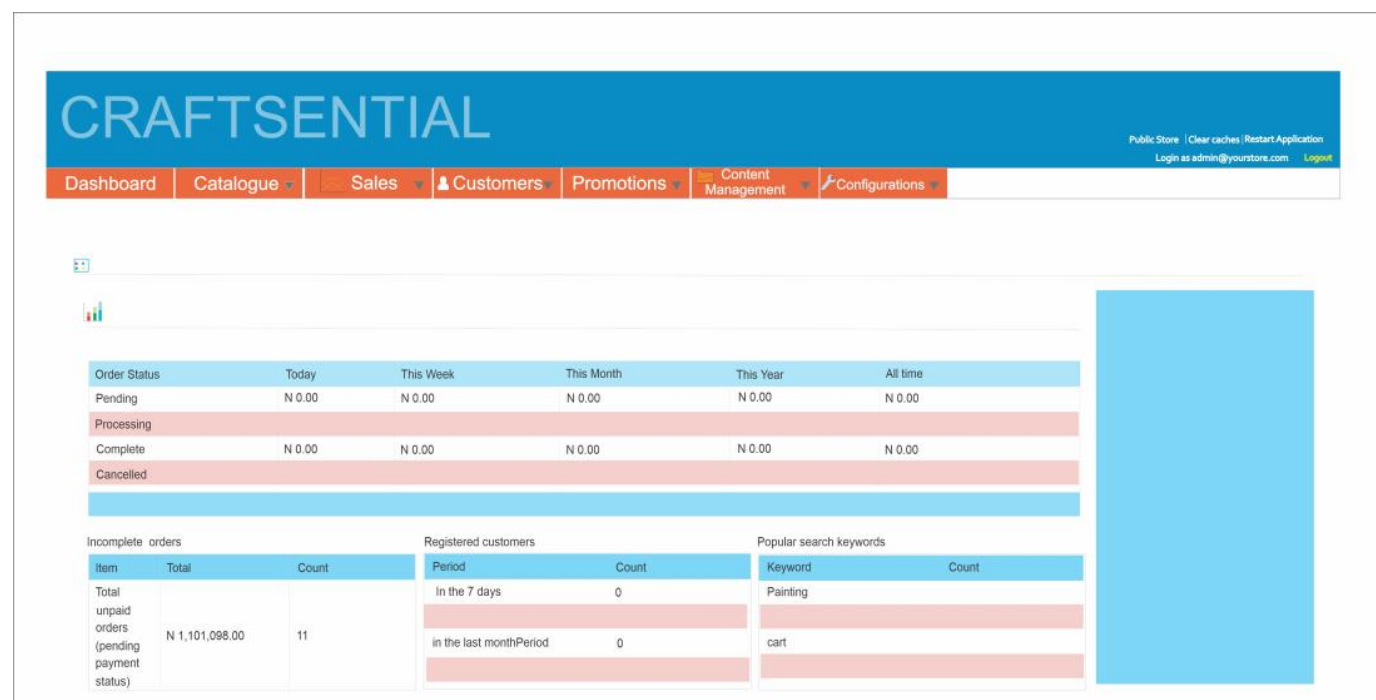

Fig. 3. Redesigned back-end of nopEcommerce Software Source: Author's fieldwork (2019)

\begin{tabular}{|c|c|c|c|c|c|c} 
Dashboard & Catalogue $\nabla$ & Sales $\nabla$ & \& Customers & Promotions $\nabla$ & Content \\
Management & $\nabla$ Fonfigurations
\end{tabular}

Fig. 4. Navigational Buttons of Redesigned back-end of nopEcommerce Software Source: Author's fieldwork (2019)

\begin{tabular}{|l|l|}
\hline Catalogue & $\bar{x}$ Sales \\
\hline Categories & Orders \\
\hline Manufacturers & Shipments \\
\hline Products & Recurring Payments \\
\hline Attributes & Return Request \\
\hline & Gift Cards \\
\hline & Current Shopping cart \\
\hline & Current Wishlist \\
\hline & Best Sellers \\
\hline
\end{tabular}

Fig. 5. Enlarged view of the Dropdown Menu of the Redesigned back-end of nopEcommerce Software

Source: Author's fieldwork (2019)

\begin{tabular}{|l|l|}
\hline Management & \multicolumn{1}{|c|}{ Content } \\
\hline Polls & Stores \\
\hline News & Countries \\
\hline Blog & Languages \\
\hline Widgets & Widgets \\
\hline Topics & Topics \\
\hline Forum & Forum \\
\hline Message templates & Message templates \\
\hline
\end{tabular}

Fig. 6. Enlarged view of the Dropdown Menu of the Redesigned back-end of nopEcommerce Software

Source: Author's fieldwork (2019) 


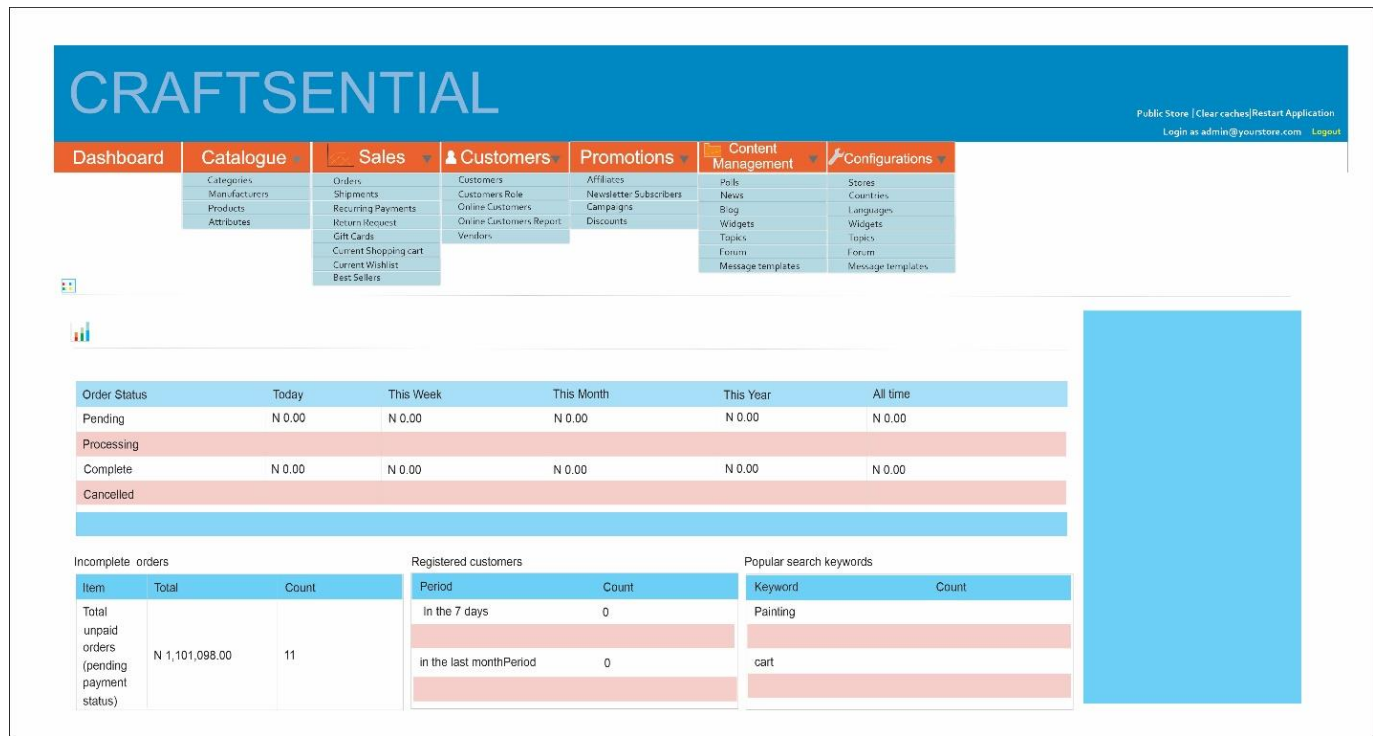

Fig. 7. Redesigned back-end with dropdown Menu of nopEcommerce Software Source: Author's fieldwork (2019)

The statistical analysis of this study utilizes the 5-point Likert scale formats Strongly Agree, Agree, Undecided, Disagree and Strongly Disagree to collect data from the population. The data collected was analyzed using mean. The nominal scores and records was attained using Likert scale model: Strongly Agree $=5$, Agree $=4$, Undecided $=3$, Disagree $=2$ and Strongly Disagree $=1$. These were calculated as $5+4+3+2+1=15 / 5=3$ (Likert Scale Criterion). The score of each item was summed and the arithmetic mean calculated for each item. The mean is compared with Likert Scale criterion above (Adepeko; Angyol). If mean is equal to or above (greater than) the Likert criterion (3.0) then the item is accepted and if the mean is lower than the Likert Scale criterion of (3.0) then the item is rejected.

\section{RESULTS AND DISCUSSION}

In this section, we have discussed the results. The following table shows the evaluation results of redesigned nopE-commerce enterprise backend.

\section{Table 1}

Evaluation Results of Redesigned nopE-commerce enterprise backend

\begin{tabular}{|c|c|c|c|c|c|c|c|}
\hline $\mathrm{S} / \mathrm{N}$ & Questions & $\begin{array}{c}\text { Strongly } \\
\text { Agree }\end{array}$ & Agree & $\begin{array}{c}\text { Un- } \\
\text { decided }\end{array}$ & Disagree & $\begin{array}{l}\text { Strongly } \\
\text { Disagree }\end{array}$ & Mean \\
\hline 1 & $\begin{array}{l}\text { Does the } \\
\text { outlook of the } \\
\text { redesigned } \\
\text { enterprise } \\
\text { backend } \\
\text { appeal to } \\
\text { you? }\end{array}$ & $\begin{array}{c}69 \\
(69 \%)\end{array}$ & $\begin{array}{c}11 \\
(11 \%)\end{array}$ & $\begin{array}{c}20 \\
(20 \%)\end{array}$ & & & 4.53 \\
\hline 2 & $\begin{array}{l}\text { Are the } \\
\text { colours of the } \\
\text { menu buttons } \\
\text { prompting? }\end{array}$ & $\begin{array}{c}76 \\
(76 \%)\end{array}$ & $\begin{array}{c}4 \\
(4 \%)\end{array}$ & $\begin{array}{c}9 \\
(9 \%)\end{array}$ & $\begin{array}{c}11 \\
(11 \%)\end{array}$ & & 4.47 \\
\hline
\end{tabular}




\begin{tabular}{|c|c|c|c|c|c|c|c|}
\hline 3 & $\begin{array}{l}\text { Are the drop } \\
\text { down menus } \\
\text { engaging? }\end{array}$ & 72 & 13 & 8 & 2 & 5 & 4.6 \\
\hline 4 & $\begin{array}{l}\text { Can the } \\
\text { colour scheme } \\
\text { of the } \\
\text { enterprise } \\
\text { backend } \\
\text { improve your } \\
\text { efficiency? }\end{array}$ & 45 & 25 & 17 & 1 & 12 & 3.8 \\
\hline 7 & $\begin{array}{l}\text { Are the texts } \\
\text { legible and } \\
\text { readable }\end{array}$ & 83 & 6 & 11 & & & 4.7 \\
\hline 8 & $\begin{array}{l}\text { Is the colour } \\
\text { scheme } \\
\text { appropriate } \\
\text { for the } \\
\text { backend of an } \\
\text { enterprise } \\
\text { software }\end{array}$ & 43 & 25 & 32 & & & 4.11 \\
\hline
\end{tabular}

Source: Authors Fieldwork 2020 (SA = Strongly Agreed, A = Agree, U = Undecided, D $=$ Disagree, $\mathrm{SD}=$ Strongly Disagree, $\mathrm{M}=$ Mean)

\section{Does the outlook of the redesigned enterprise backend appeal to you?}

The outlook of the redesigned e-commerce enterprise backend appeal to the target users (Mean= 4.5). Colours are emotive and persuasive in influencing actions and feelings. The human sub-consciousness is awakening by exciting and contrasting colours. The combination of blue and orange colours enriches interpersonal relationship in a working environment. Colour subconsciously capture a human's attention and is used to trigger behavioral responses which range from encouraging the sale of a product, sharing content, or subscribing to a blog (Machleit and Davis 564).

\section{Are the colours of the navigation buttons prompting?}

The navigation buttons of the redesigned e-commerce enterprise software backend are prompting (4.5). According to Joseph Azi, colours are necessary for visual accentuation. The clickable navigation buttons are the usability gateways of the ecommerce enterprise backend. Application of dark orange colour on the navigation buttons was predicated on the psychological properties of orange which arouses both physical and the emotional reactions. However, the percentage of red is more than yellow because red stimulates physical courage, vigour, balminess, basic survival, inspiration, maleness, enthusiasm, lively and approachable (Pelet)

\section{Are the drop-down menu buttons engaging?}

The drop-down menu buttons are engaging (Mean=4.6). Drop down menus appears when any of the navigation buttons is clicked. These drop-down menus have light blue colour and subtle shadows that create dramatic effects when clicked. Light applied to each of the box like drop down menus because of the calmness of blue colour. 
The user really needs to be focused and calm to be able to interact appropriately with the drop-down menus.

\section{Can the colour scheme of the redesigned enterprise backend improve your efficiency?}

The colour scheme of the redesigned enterprise backend can improve the efficiencies of users (Mean=4.5). Apparently, contrasting colours are vibrant and engaging. Vibrant functionalities of enterprise backend platforms improve the effectiveness of users. It invites users into the application and creates a form of excitement for the users when they are bored or fag out. Kendra Cherry asserted that blue colour stabilizes mood

\section{Are the texts legible and readable?}

The respondents agreed that the texts are legible and readable $(M e a n=4.7)$. The texts are in black colour. Colour is important element that aid readability and memorization of information and navigation on an e-commerce platform (Pelet). Texts constitute the physical body of content that facilitate the understanding of an information. In design, the choice of typeface, its readability, legibility and appealing display often stimulate users' interest.

\section{Is the colour scheme appropriate for the backend of an enterprise software?}

The colour scheme is the backend of an enterprise software (Mean=3.8). It is apparent that the psychological perception of these two colours underscores their appropriateness in an office environment. The functionalities of the redesigned backed enterprise software are not downplayed by poor interface design.

The psychological properties of orange include strength, energy warmth, stimulating intelligence, delight, and liveliness. These makes the colour suitable as the adorning colour for the menu buttons on the navigation bar. It invites users into the application and creates a form of excitement for the users when they are bored or fag out. Blue colour triggers astuteness, communication, confidence, competence, calmness, duty, reason, freshness, reflection and concentration (Pelet). Blue is also considered to motivate productivity. The clickable menu bars have drop down menus which have light blue colours and subtle shadows that create dramatic effects when clicked. The slim box like column beneath the order status have light red and blue colours to create contrast and lively interest.

\section{Major Findings}

1. Colours stimulate actions and feelings.

2. User interface colours in virtual environment determines the efficiency of the system.

3. Creative interplay of orange and blue colour in e-commerce back-end user interface enhances the performance of backend managers.

4. Colours have psychological and physiological impacts on people.

\section{Conclusion}

The user interface of e-commerce enterprise backend is essential in enhancing user's performance on the software. Enterprise backend being a virtual office also need to reflect the features of a physical office for optimal efficiency. Usually, the administrators of backend of enterprise solutions manages the virtual office throughout the working hours and even beyond. Hence the administrators are often under pressure to feed in necessary information into the software. Aesthetics ingrained of the backend user 
interface subtly appeal to the subconscious of the user thereby refocusing and enabling his effectiveness. The ambience of office environment motivates productivity. Therefore, the developers of e-commerce enterprise backend functionalities should consider the psychological and physiological reactions of users that interact with the system.

\section{Works Cited}

Adepeko, O. A. "Survey of Ondo Traditional Hand Woven Fabrics and their Modifications to Suit Contemporary Fashion Trends in Nigeria." Doctoral Thesis. Department of Industrial Design, Ahmadu Bello University Zaria, 2016.

Angyol, Adawus. "Development of Alphabet Multimedia Instructional Materials to Enhance Pre-Primary Pupils Education in Samaru Zaria, Kaduna State Nigeria." Masters Dissertation. Department of Industrial Design, Ahmadu Bello University Zaria, 2015.

Aronhamukwaya. "Graphical User Interface." PROGRAMMING - GUI and RAD, https://www.aronhamukwaya.gitbooks.io. Accessed 12 Sept. 2018.

Azi, Joseph. Class Discussions on E-commerce Website Design and Development. Department of Industrial Design, Ahmadu Bello University Zaria. https://industrialdesign.abu.edu.ng/. Accessed 23 Dec. 2018.

Beal, Vangie. "Alpha Version.” Webopedia, 13 March 1998, https://www.webopedia.com/definitions/alpha-version/. Accessed 8 Oct. 2016.

Castro, Doris. "How Much Does Backend Maintenance of Mobile App Cost?" Quora, 28 March 20, www.quora.com. Accessed 5 July 2020.

Cherry, Kendra. "Color Psychology: Does It Affect How You Feel? How Colors Impact Moods, Feelings, and Behaviors." 27 March 2019, www.dotdash.com. Accessed 16 Dec. 2020.

Ciotti, Gregory. "The Psychology of Colour in Marketing and Branding." Textile Learner, 9 Dec. 2020, https://www.helpscout.net. Accessed 12 June 2019.

Coates, Dell. Watches tell more than time. McGraw-Hill, 2003.

Glasskeys, Stephen. "Create an Online Store in Minutes with nopCommerce." IT World, 17 March 2015, https://www.itworld.com/article/2897652/use-nopcommercecreate-an-online-store-in-minutes.html. Accessed 05 September 2017.

Gube, Jacob. "What Is User Experience Design? Overview, Tools and Resources." On SmashingMag, 5 Oct. 2010, https://www.smashingmagazine.com/2010/10/whatis-user-experience-design-overview-tools-and-resources/. Accessed 10 October 2015.

Hallock, Joe. "Colour Assignment." Joe Hallock, https://www.joehallock.com/edu/COM498/credits.html. Accessed 18 Oct. 2019.

Hoots, Kate. "What Is Enterprise eCommerce Software \& How Can You Find the Right Platform?" Merchant Maverick, 20 May 2017, https://www.merchantmaverick.com/what-is-enterprise-ecommerce-software/. Accessed 22 Nov. 2020.

Imel, Ryan. "WooThemes Forks Jigoshop into WooCommerce, WooLabs." WPCandy, 25 August 2011, https://en.wikipedia.org/wiki/WooCommerce. Accessed 18 August 2020.

John, Sameer. "What is E-commerce, History, Future." Slideshare, 15 Dec. 2011, https://www.slideshare.net/sameer john/what-is-e-commercehistoryfuture. Accessed 20 May 2018.

Jordan, Patric W. Designing Pleasurable Products: An Introduction to the New Human Factors. Routledge, 2000. 
Kim, Jinwoo, Jungwon Lee, Kwanghee Han and Moonkyu Lee. "Businesses as Buildings: Metrics for the Architectural Quality of Internet Businesses." Information Systems Research, vol. 13, no. 3, September 2002, pp. 239-254.

Laudon, Jane P. and Laudon, Kenneth C. Essentials of Management Information Systems ( $8^{\text {th }}$ ed.). Pearson, 2008.

Lindgaard, Gitte and Dudek, Cathy. "What Is This Evasive Beast We Call User Satisfaction?" Interacting with Computers, 1 June 2003, https://academic.oup.com/iwc/article-abstract/15/3/429/773082. Accessed 23 Jan. 2019.

Mattila. Anna S. and Wirtz, Jochen. "The Role of Store Environmental Stimulation and Social Factors on Impulse Purchasing." Journal of Services Marketing, vol. 22, no. 7, 2008, pp. 562-567.

“nopCommerce." Solution Partners, n.d, https://www.nopcommerce.com/en/solutionpartners. Accessed 5 September 2017.

Norman, Don A. "Emotion and Design: Attractive things Work Better." Interactions Magazine, vol. ix, no. 4, 2002, pp 36-42.

Pelet, Jean. Effects of the Colours of E-Commerce Websites upon Memorization and Intent of Buying. 13th AIM Conference (pre-ICIS Workshop), Paris, France. 2008.

Petit, Nick. "Which Layout? Static, Liquid, Adaptive, or Responsive." treehouse, 22 July 2014, https://blog.teamtreehouse.com/which-page-layout. Accessed 25 Jan. 2020.

Schwarz, Lisa. "What is an E-commerce Platform." Oracle netsuite, 18 April 2016, https://www.netsuite.com/portal/resource/articles/ecommerce/what-is-anecommerce-platform.shtml. Accessed 29 March 2020.

Tractinsky, Noam, A.S. Katz and D. Ikar. "What Is Beautiful Is Usable." Interacting with Computers, vol. 13, no. 2, 2000, pp. 127-145.

"WooCommerce Genesis Framework for Woocommerce." Studio Press, 28 September 217, https://woocommerce.com/experts/. Accessed 11 Sept. 2020. 